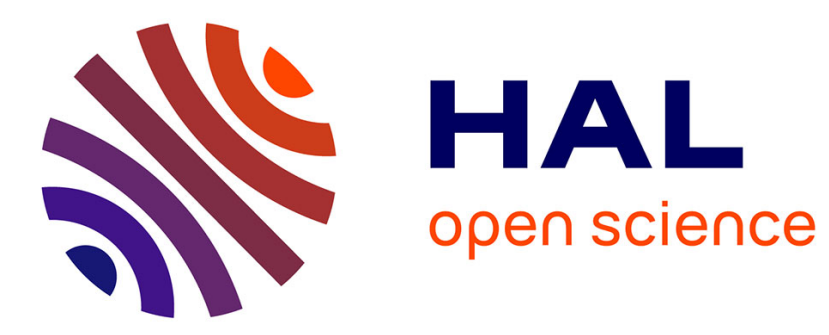

\title{
Design optimization using Statistical Confidence Boundaries of response surfaces: Application to robust design of a biomedical implant
}

Laetitia Rossi, Jean-Marc Linares, Julien Chaves-Jacob, Jean Mailhé, Jean-Michel Sprauel

\section{To cite this version:}

Laetitia Rossi, Jean-Marc Linares, Julien Chaves-Jacob, Jean Mailhé, Jean-Michel Sprauel. Design optimization using Statistical Confidence Boundaries of response surfaces: Application to robust design of a biomedical implant. CIRP Annals - Manufacturing Technology, 2014, 63 (1), pp.141-144. hal01303708

\section{HAL Id: hal-01303708 \\ https://hal.science/hal-01303708}

Submitted on 19 Jan 2017

HAL is a multi-disciplinary open access archive for the deposit and dissemination of scientific research documents, whether they are published or not. The documents may come from teaching and research institutions in France or abroad, or from public or private research centers.
L'archive ouverte pluridisciplinaire HAL, est destinée au dépôt et à la diffusion de documents scientifiques de niveau recherche, publiés ou non, émanant des établissements d'enseignement et de recherche français ou étrangers, des laboratoires publics ou privés. 


\title{
Design optimization using Statistical Confidence Boundaries of response surfaces: Application to robust design of a biomedical implant
}

\author{
Laetitia Rossi $^{\text {a,b }}$, Jean-Marc Linares $(2)^{\text {a,b,* }}$, Julien Chaves-Jacob ${ }^{\text {a }}$, Jean Mailhe ${ }^{\text {a }}$, \\ Jean-Michel Sprauel ${ }^{\mathrm{a}}$ \\ a Aix-Marseille Universite, CNRS, ISM UMR 7287, 13288 Marseille, Cedex 09, France
b Biotech International, 305 Allees de Craponne, 13300 Salon de Provence, France \\ This paper deals with the use of Statistical Confidence Boundaries (SCB) of response surfaces in robust \\ design optimization. An empirical model is therefore selected to describe a real design constraint \\ function. This constraint is thus approximated by a second order polynomial expansion which is fitted to \\ numerical simulations that use a Finite Element Method (FEM). A technique is also proposed to analyze \\ the effects of the uncertainties of the inputs of the simulations. This approach is employed to optimize the \\ design of a biomedical wrist implant. A real optimized implant is then manufactured and tested to \\ validate the numerical model
}

Keywords:

Design optimization Uncertainty Biomedical

\section{Introduction}

In the common life, wounds can appear, due to sports activities or accidents in the home. Often, prostheses or implants are then used to restore the functional capacity of the patient [1]. The design of biomedical products is however constrained by many criteria (biocompatibility of the materials, lifespan of the implant, small available geometrical space...) and needs multi-objective optimization methods. An overview of Design Theories and Methodologies (DTM) was already presented in a keynote paper [2]. The prescriptive models for design were thus discussed (canonical design process, morphological analysis and prescriptive models of the design artefacts, Suh's Axiomatic Design and Taguchi Method). These DTM methods can be used to enrich the functional and attributive information of design solutions. Different approaches are then employed to characterize the Design Solution Surface (DSS). The proposed models can thus be classified with two different points of view: Global/local description and Analytical/ Numerical modelling. As example, the optimization of the deflection of a cantilever is presented in Fig. 1. The first approach allows calculating the design solution for any set of input parameters. The quality of the results also only depends on the accuracy of the model. Generally, the time and cost to develop a global analytical model are however significant. For that reason, empirical models are employed in the second approach to describe the real design constraint function. Usually, a polynomial model is then locally best fitted to the real DSS, using a limited number of numerical simulations or real experiments. A design of experiment (DOE) technique can therefore be employed to define the optimal set of input parameters of this approach. Optimization of the design parameters is however limited to the local domain used for fitting. In the third approach a single numerical simulation is carried out, just to check that the design constraints are satisfied for the given selected set of inputs. This simulation is usually based on a Finite Element Model (FEM). In the last approach, the numerical simulation is repeated many times to get a global view of the DSS. This method, however, only provides a discrete description of the DSS. In the second approach, the quality of the best fit is a central property for the accuracy of the optimization. In some works [3,4], the major components of Engineering Design Optimization (EDO) were classified in five entities: design variables, constraints, objective functions, problem domain and environment. Their uncertainties or variations are propagated to the optimized design solution to check the robustness of the design [5]. This permits also verifying that the design requirements will be satisfied for all manufactured products. Robust design optimization [6-8] can be used to design biomedical products. Roy et al. conclude their keynote paper with this sentence: "there is a lack of research in multi-objective design optimization that deals with

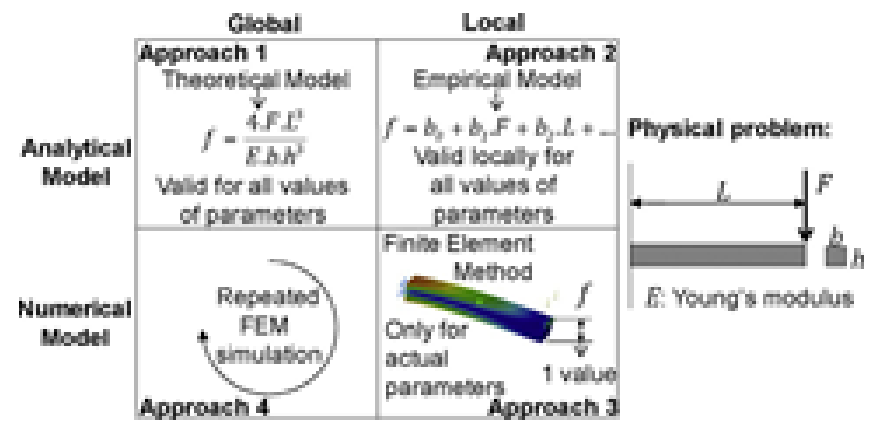

Fig. 1. Different approaches to characterize design solution surfaces. 
uncertainty and constraints together" [3]. In this context, the aim of our paper is to use the Statistical Confidence Boundary (SCB) of response surfaces in design of experiment-based optimization.

\section{Presentation of the method}

This section presents the methodology used to get the response surface and the related SCBs, of a DSS characterized by FEM simulations. As example, the approach will focus on a problem with two factors (U1 and U2). The response surface will be approximated by the second order polynomial empirical model described by Eq. (1).

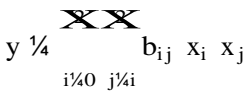

where $x_{0}=1 . x_{1}, x_{2}$ are the normalized values of factors U1, U2 .

The different possible shapes of response surfaces are drawn in Fig. 2. A DOE strategy permits defining the optimal set of inputs (U1, U2) to be employed for the FEM simulations. The coefficients of the polynomial model are then derived from the FEM results using the following pseudo-inverse calculation:

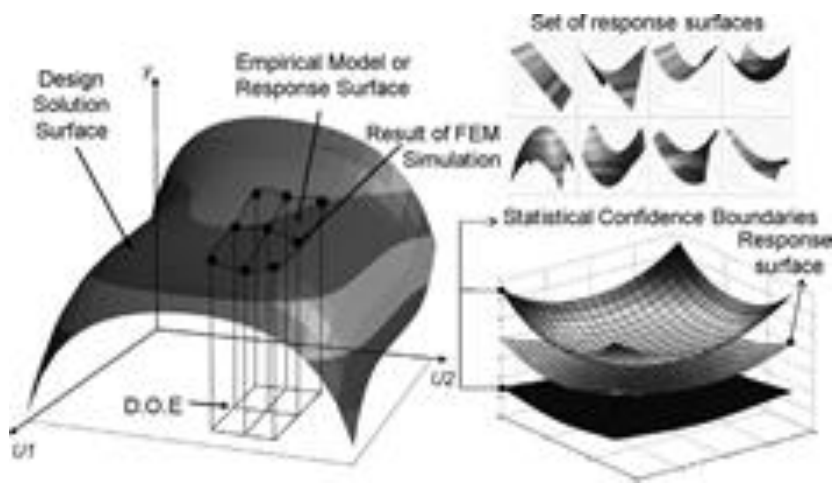

Fig. 2. Principle of D.O.E based optimization.

Y $1 / 4 \mathrm{X}$ B with $\mathrm{X}$ the matrix of the normalized products $x_{i} x_{j}$ and $B$ : the response surface coefficients vector

B $1 / 4 \partial X^{T} X p^{\ddot{y} 1} X^{T} Y$

$\hat{B}$ defines the best estimate of the surface response coefficients

A propagation method is then implemented to account for the uncertainties of the input parameters and the inaccuracy of the model. The scatter of the material properties, design parameters and manufacturing conditions is assumed random and normal distributed. It is described by standard deviations (S).

The inaccuracy of the fitting model is characterized by the root mean square (Rms) of the differences between the FEM simulation results and the mean local polynomial used to describe the DSS Variations of the environment are not taken into account in this study. The scheme used to propagate the different deviations to the SCB is presented in Fig. 3.

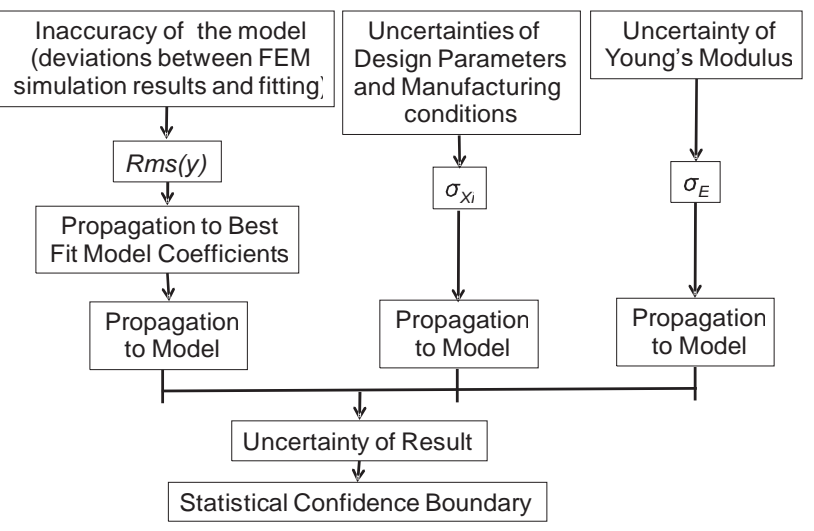

Fig. 3. Uncertainty and Error Propagation scheme.

\subsection{Propagation of the inaccuracies of the fitting model}

The inaccuracy of the model is represented by the root mean square Rmsðyp of the best fit residues R calculated through Eq. (3).

$R 1 / 4 Y \ddot{y} X \hat{B}$

The mean square error matrix MSEðB̂P of the response surface coefficients is then calculated using following expression:

$$
\begin{aligned}
& \text { MSEðB̂p 1/4 MSEððX } X^{\mathrm{T}} \mathrm{p}^{\ddot{y}^{1}} \mathrm{X}^{\mathrm{T}} \mathrm{Yp} \\
& \text { MSEðB̂ } 1 / 4 \partial X^{T} X p^{\ddot{y} 1} \text { Mseðyp } 1 / 4 \partial X^{T} \quad X p^{\ddot{y} 1} \text { Rmsðyp }
\end{aligned}
$$

This permits finally evaluating the mean square error Mseðŷ́p of the design solution $\hat{y}$ estimated for any set of input parameters. Following classical propagation method is used for that purpose:

Mseðŷy 1/4 $\mathrm{J}_{\hat{\mathrm{B}}}$ MSEðB⿱⺈ J ${ }_{\hat{\mathrm{B}}}^{\mathrm{T}}$

with, $J_{\hat{B}}$; Jacobian of function $\hat{y}$ with respect to coefficients $b_{i j}$.

\subsection{Propagation of the uncertainties of the design parameters}

The scatter of the design parameters is usually characterized by Tolerance Intervals (TI) that are either imposed by the designer or derived from the capability of the manufacturing process. If a Gaussian Probability Density Function (PDF) is assumed for a given input parameter $\mathrm{x}_{\mathrm{i}}$, the standard deviation $\mathrm{S}_{\mathrm{xi}}$ can be derived from the tolerance interval $\mathrm{TI}_{\mathrm{i}}$ through following expression:

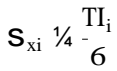

Assuming the independence of the two parameters $x_{1}, x_{2}$, the standard deviations are then propagated to the response surface using Eq. (7).

$\operatorname{Var} \partial \hat{y} p 1 / 4 J_{x i} \operatorname{VAR} \partial x_{i} p J_{x i}{ }^{T}$

with, $\mathrm{J}_{\mathrm{xi}}$, Jacobian of function $\hat{\mathrm{y}}$ with respect to $\mathrm{x}_{\mathrm{i}}$

$$
\text { VAR } \partial x_{i} p 1 / 4 \begin{array}{cc}
T^{2}=36 \\
1
\end{array} \quad T_{2}=36 \text { is the covariance matrix of } x_{i} \text {. }
$$

2.3. Propagation to load and stress, of the scatter of the material properties, in the case of a pure elastic behaviour

Mechanical tests (tensile tests) are usually carried out to characterize the material properties. They allow defining the mean Young's modulus E of the material, and the related standard deviation $\mathrm{S}_{\mathrm{E}}$. Common constrains imposed in design optimization are the maximum stress (S) or applied load (L) to which the structure must resist. In the case of imposed displacements, and pure elastic behaviour of the material, the resulting applied Load and stress are proportional to Young's modulus. This leads to following relationships:

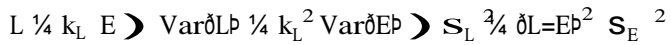

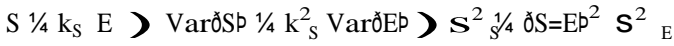

\subsection{Response surface and Statistical Confidence Boundary}

Previous calculations are used to evaluate the design solution $\hat{y}$ for any set of input parameters and estimate its mean square error (Eq. (10)).

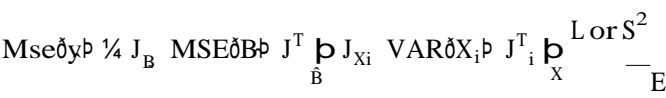

$$
\begin{aligned}
& \text { Varð̄Ep }
\end{aligned}
$$

With smooth design solution surfaces, the model inaccuracy remains small in comparison to the random perturbations of the inputs that are assumed to be normal distributed. The global distribution is therefore close to a Gaussian. The SCBs of 
the response surface can thus be approximated in the following way:

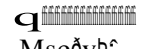

$$
\begin{aligned}
& \text { SCB } 1 / 4 \text { ŷ k Mseðyp; k } 2 \text { for a confidence level of } 95 \% \text { : }
\end{aligned}
$$

\section{Application to the design of a biomedical wrist implant}

The function of the studied biomedical implant is to substitute the natural ligament between two bones of the wrist. Experiments of the literature show that the Young's modulus E of the ligament is ranged between 50 and $100 \mathrm{MPa}$ [9]. If assuming a uniform PDF and a risk of 5\%, this leads to the confidence interval $\mathrm{E}=7510 \mathrm{MPa}$. The maximum elongation of the ligament and its torsion angle were estimated by Upal et al. [10] to about $0.9 \mathrm{~mm}$ and 158 respectively. The material selected for the implant is PolyEther Ether Ketone (PEEK) which is a biocompatible thermoplastic organic polymer. Its Young's modulus was evaluated by tensile tests to $\mathrm{E}_{0}=3582127 \mathrm{MPa}$ (confidence level 95\%). In relation to the fatigue limit, the maximum stress that can be applied to the material is restricted to $90 \mathrm{MPa}$. The maximum overall dimensions of the implant were specified by the surgeon to $181812 \mathrm{~mm}$.

\subsection{Implant design driven by material properties}

The functionality of the implant is to reproduce the mechanical behaviour of the ligament. This imposes designing an implant with a very low stiffness, which is not directly compatible with the elastic modulus of PEEK. One way to overcome this impediment is to create an elementary pattern with holes. The equivalent Young's modulus of such volume can then be evaluated through a micro-mechanical approach of porous materials. Fig. 4 shows the predictions of the classical Voigt and Hill models. Both models lead to simple linear expressions (Eqs. (12) and (13)) that permit evaluating the density of holes required to adjust the stiffness of the elementary peek pattern to the Young's modulus of the ligament. Hill's approach, which is the most accurate in the case of random repartitions of voids, predicts that the material loses its consistency when the porosity exceeds $50 \%$.

$E^{1 / 4} E_{0} \ddot{y} 2 E_{0}$ p ) p p 1/4 $\frac{E_{0} \ddot{y} E_{0}}{2 E_{0}} 49 \% ; \quad$ Hill Model

$\left.E^{1 / 4} E_{0} \ddot{y} E_{0} \quad p\right) p 1 / 4 \frac{E_{0}}{E_{0}} E_{1 / 4} 97 \% ; \quad$ Voigt Model

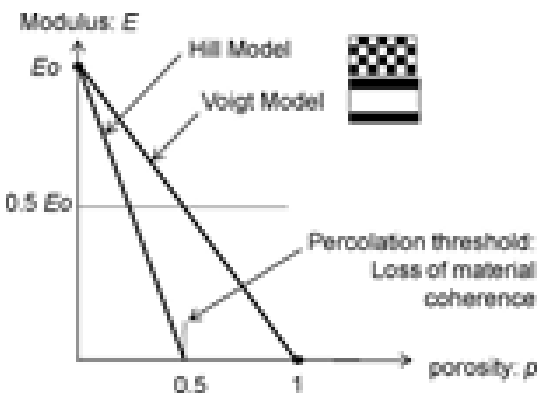

Fig. 4. Modulus evolution versus porosity and topology.

These two equations bring to the fore how it is difficult to obtain an implant that owns stiffness compatible with the elastic behaviour of the natural ligament. To accept the applied displacements $(0.9 \mathrm{~mm}, 158)$ and reproduce the behaviour of the natural ligament (toe and linear regions in Fig. 5), the design of the proposed implant is based on two springs (with respective rate K1 and $\mathrm{K} 2$ and $\mathrm{n}_{1}, \mathrm{n}_{2}$ number of windings) mounted in parallel with two stops $\left(e_{1}\right.$ and $\left.e_{2}\right)$.
Fig. 5 presents the rheological scheme of the implant. The first spring K1 was dimensioned to accept a torsion angle of 158 and an elongation of $0.9 \mathrm{~mm}$. The second spring $\mathrm{K} 2$ was calculated to bring an elongation of $0.3 \mathrm{~mm}$. The stop device $e_{2}$ is a titanium cable designed to carry the final load.

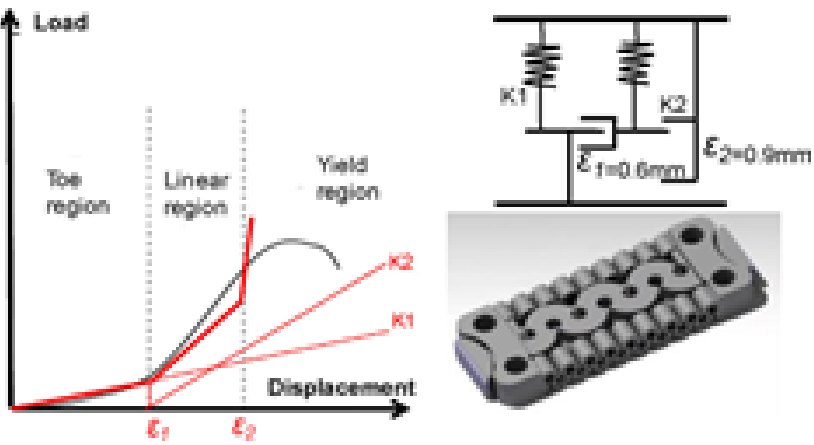

Fig. 5. Behaviours of the natural ligament and the designed product.

\subsection{Optimization methodology}

The spring K2 was studied first. Each of its windings consists of an elementary pattern (central part) that was optimized through a DOE methodology. This pattern is shown in Fig. 6. It is characterized by two main parameters: a width $\mathrm{U} 1$ and a radius U2. In Fig. 5, the number of windings $\left(n_{2}\right)$ was fixed to 3 .

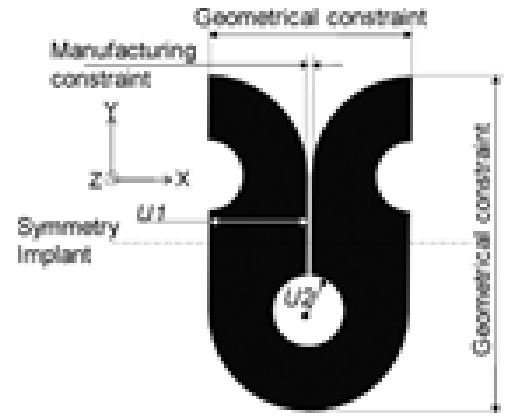

Fig. 6. Design of the elementary pattern of spring K2

The mechanical behaviour of the elementary pattern was characterized by FEM simulations. Nine configurations were thus studied. The composite DOE matrix, presented in Table 1, was therefore used to define the optimal set of design parameters U1, $\mathrm{U} 2$ to be employed for the simulations.

Table 1

Design factors (U1, U2) and related normalized factors $\left(\mathrm{x}_{1}, \mathrm{x}_{2}\right)$ for $\mathrm{n}_{2}=3$.

\begin{tabular}{lrll}
\hline $\mathrm{U} 1(\mathrm{~mm})$ & $\mathrm{x}_{1}$ & $\mathrm{U} 2(\mathrm{~mm})$ & $\mathrm{x}_{2}$ \\
\hline 1.5 & $\ddot{y} 1$ & 0.45 & $\ddot{y} 1$ \\
2 & 1 & 0.45 & $\ddot{y} 1$ \\
1.5 & $\ddot{y} 1$ & 0.65 & 1 \\
2 & 1 & 0.65 & 1 \\
1.5 & 0 & 0.55 & 0 \\
2 & 0 & 0.55 & 0 \\
1.75 & 0 & 0.45 & 0 \\
\hline
\end{tabular}

For each configuration, the FEM calculations permitted defining the maximum equivalent stress $S$ of the material and the total load $\mathrm{L}$ applied to the spring at its maximum imposed elongation of $0.3 \mathrm{~mm}$. The mean response surfaces of the stress $\left(\hat{y}_{\mathrm{S}}\right)$ and the load $\left(\hat{y}_{\mathrm{L}}\right)$ versus the two factors $\mathrm{U} 1, \mathrm{U} 2$, and the associated SCBs were finally derived from the nine performed simulations. These two response surfaces are shown in Fig. 7. 
